\title{
Understanding the Split Characteristics of the Tropical Mesoscale Convective System (MCS) of April 9, 2018, in Northern Ghana Using Infrasound Data
}

\author{
K. Benjamin Kouassi ${ }^{1,2 *}$, Fidele Yoroba ${ }^{1,2}$, Uchenna Onwuhaka Madu³, Adama Diawara ${ }^{1,2}$, \\ Kouakou Kouadio1,2, Paul Antoine Yao ${ }^{1}$
}

${ }^{1}$ Laboratoire des Sciences de la Matière, de l'Environnement et de l'Energie Solaire (LASMES), UFR-SSMT, University FHB, Abidjan, Côte d'Ivoire

${ }^{2}$ Station Geophysique de Lamto, N’Douci, Cote d'Ivoire

${ }^{3}$ Nigeria Atomic Energy Commission, Abuja, Nigeria

Email: ^benjamin.kouassi@gmail.com

How to cite this paper: Kouassi, K.B., Yoroba, F., Madu, U.O., Diawara, A., Kouadio, K. and Yao, P.A. (2021) Understanding the Split Characteristics of the Tropical Mesoscale Convective System (MCS) of April 9, 2018, in Northern Ghana Using Infrasound Data. Atmospheric and Climate Sciences, 11, 1-10.

https://doi.org/10.4236/acs.2021.111001

Received: October 8, 2020

Accepted: November 28, 2020

Published: December 1, 2020

Copyright $\odot 2021$ by author(s) and Scientific Research Publishing Inc. This work is licensed under the Creative Commons Attribution International License (CC BY 4.0).

http://creativecommons.org/licenses/by/4.0/ (c) (i) Open Access

\begin{abstract}
The split characteristics of the tropical Mesoscale Convective System (MCS) of April 9, 2018, in northern Ghana were studied using infrasound data measured by the mobile array (I68CI) which was deployed by Côte d'Ivoire National Data Center (NDC) in collaboration with the Comprehensive Nuclear-Test-Ban Treaty (CTBT). These infrasound measurements were made during a measurement campaign from January $1^{\text {st }}, 2018$ to December 31, 2018, in northeast Cote d'Ivoire, precisely in Comoe National Park. Graphic Progressive Multi-Channel Correlation (GPMCC) method based on a progressive study of the correlation functions was used to analyze and visualize data. The infrasound detection from this MCS shows clearly a division of the MCS structure into 2 distinct subsystems under the effect of internal and external constraints not well known but related to convection; a smaller subsystem in the north, associated with an area of intense rainfall of about 30 $\mathrm{mm} /$ hour and located at $9.5^{\circ} \mathrm{N}-2^{\circ} \mathrm{E}$ with an azimuth of $70^{\circ}$ and, a large subsystem in the south, associated with a zone of high rainfall of about 96 $\mathrm{mm} /$ hour and located at $8.8^{\circ} \mathrm{N}-1.4^{\circ} \mathrm{E}$ with an azimuth of $90^{\circ}$. These two subsystems were located $200 \mathrm{~km}$ and $260 \mathrm{~km}$ from the I68CI station with frequencies of $2.3 \mathrm{~Hz}$ and $1 \mathrm{~Hz}$ respectively. The mesoscale convective systems in this region are moving from East to West and including several storm cells.
\end{abstract}




\section{Keywords}

Infrasound, Mesoscale Convective Systems (MCS), Cote D'Ivoire, Satellite Image

\section{Introduction}

The Comprehensive Nuclear-Test-Ban Treaty (CTBT) established an International Monitoring System (IMS) consisting of a network of radionuclide, hydroacoustic, seismic, and infrasound measurements to detect and locate nuclear explosions. This network of measurements is of great interest in many scientific fields because it allows continuous monitoring of human activities (e.g. any types of explosions, quarry shots, etc.) and natural phenomena (gravity waves, sprites, erupting volcanoes, thunderstorms, etc.) at a global scale [1]. The infrasound network is composed of 60 stations across the surface of the globe [2]. These stations are equipped with micro-barometers that provide high-quality data that can be used to study a very large number of natural or non-natural events that can spread over tens of thousands of kilometers. In this list, we can have meteorite re-entry, erupting volcanoes [3] [4], avalanche phenomena, gravity waves [5], bolides [6], sprites [7], any types of explosions or quarry shots and also Mesoscale Convective Systems (MCSs) or thunderstorms [8]. Techniques for processing these data using statistical correlation methods are also used to determine wavefront characteristics (e.g. azimuth, velocity, frequency, etc.).

Unlike other regions such as Europe and America, in West Africa there are few nearby infrasound stations to determine regional and local events whose frequency bands are 1 to $2 \mathrm{~Hz}$ and $>2 \mathrm{~Hz}$ respectively. However, a so-called local or regional event can be detected in either frequency band because the atmospheric propagation of infrasound signals can be modified by weather conditions (wind, temperature, etc.). Better localization of these events requires measurements from at least two nearby stations. Indeed, the data measured by a single infrasound station do not allow precisely locating the emitting sources by cross-referencing azimuths, which have the advantage of differentiating the nature of the sources (point sources and mobile sources) on the one hand, and characterizing events (regional and local events) on the other hand.

Besides, the few existing infrasound stations in Africa (I48TN in Tunisia, I11CV in Cape Verde, IS50 in Ascension, and I17CI in Cote d'Ivoire) are quite far from each other to address the technical specifications developed by the CTBT. This situation makes quite difficult the study of MCSs and their location because they are local and/or regional events.

In Cote d'Ivoire, the detections of the I17CI station seem to be dominated by local and regional infrasound sources, while the bulletins established by the International Data Center (IDC) in Vienna (Austria) contain for the region the distant events. 
It is in this context that the project to deploy a portable array (I68CI) was released in January 2018 in the north-eastern part of Côte d'Ivoire, specifically in the National Park of Comoé at the initiative of researchers from the Station Geophysique de Lamto in collaboration with CTBT through IMS and IDC in Vienna to establish with I17CI station an efficient observation and monitoring network. This exceptional network allows characterizing local and regional infrasound sources in the detection bulletins of Cote d'Ivoire NDC (Lamto Station). Moreover, infrasound emission sources over West Africa are known to be multiple sources such as gravity waves, microbaroms, mines but also MCS, etc.

Concerning the MCSs, the work of [8] over West Africa using the data from I17CI station emphasized that lightning flashes observed from space show a similar infrasonic acoustic signal with thunderstorms, which is came mainly from the gravity waves activity over West Africa. Also, gravity wave activity periods correspond to the MCSs seasons observed near the I17CI station. These authors also found that the thunderstorm activity is very low in January similar to the gravity wave activity, and showed seasonal variations, including two activity periods in March-June and October-December.

In the same vein, some studies [9] [10] have shown that the main cause of interannual rainfall variability in West Africa is related to the number of MCSs. These mesoscale disturbances represent extreme weather events contributing to more than $90 \%$ of rainfall in the Sahel region [11]. Thus, to better characterize such perturbations, the authors [12] analyzed the characteristics of tropical MCSs over West Africa using the regional climate model MAR. They found that regional climate models can reproduce the main features of the MCSs despite some differences with observations. However, MCSs or tropical storms are composed of independent convective cells that merge and/or separate when convection weakens [11].

The proposed work aims to study this separation characteristic of convective cells using the infrasound signals emitted by thunderstorms during their life cycle. The studied MCS was initiated on April 8, 2018, between 5:00 and 6:00 pm. Indeed, April is the month of the first rainy season over West Africa where MCSs are found. This study is structured as follows; Section 2 is dedicated to the description of the materials and the method used. Section 3 shows the results and, the discussion is given in section 4 . Finally, the conclusion and perspectives are given at the end.

\section{Data and Method}

\subsection{Materials}

The IMS Portable Network I68CI was deployed from January 1, 2018, to December 31, 2018, in the northeast of Côte d'Ivoire, in the Comoe National Park to record one year of infrasound signals. This network consists of 4 boxes labeled $168 \mathrm{H} 1, \mathrm{I} 68 \mathrm{H} 2, \mathrm{I} 68 \mathrm{H} 3$, and $\mathrm{I} 68 \mathrm{H} 4$ following an equilateral triangle with one 
sensor in the centre. The opening of the network is about $1 \mathrm{~km}$. In this device, the sensor I68H1 was the central element. Each box is composed of a micro-barometer sensor MB3d, a GPS, a $12 \mathrm{~V}$ power supply battery, four porous pipes, and a reduction system (WNRS) of the disruptive effects of wind. Resolutions of a few $\mathrm{hPa}(0.01$ to $27 \mathrm{hPa})$ are used over the entire band of interest, which in our case ranges from 0.01 to about 50 Hertz. This calibration allows the observation of large-amplitude events near the station and small amplitude signals from distant sources. A low power consumption digitizer is also incorporated. Besides, the rainfall database of April 92018 associated with this study is derived from the hourly rainfall satellite estimation [13] [14] of the Global Satellite Precipitation Mapping Project (GSMaP, https://sharaku.eorc.jaxa.jp/GSMaP/), of the Japan Science and Technology Agency (JST). This project was initiated in 2002 and promoted by the Japan Aerospace Exploration Agency (JAXA) since 2007. The GSMaP rain product is based on using 4 satellite microwave radiometers combined with Geo Infrared radiometer data to produce $0.1^{\circ}$ spatial resolution [15].

\subsection{Method}

The infrasound signals data of April 92018 processing uses the Progressive Multi-Channel Correlation (PMCC) Method, based on a progressive study of the correlation functions leading to a consistent set of time-delays in the case of a coherent propagating wave [16]. Indeed, the mobile array I68CI is composed of four micro-barometers forming a triangle of $\sim 1 \mathrm{~km}$ basis with a central point which is a typical configuration of International Monitoring System (IMS) stations. Such stations form sensitive acoustical antennas. The computation of the consistent set of time-delays $\Delta t_{i j}$ derived from an analysis of the set of cross-correlation functions of each couple of antennas $i$ and $j$. In this case, the consistency was defined by the inverse of the RMS of the residuals $r_{i j k}$ of the triangular relation: $r_{i j k}=\Delta t_{i j}+\Delta t_{j k}+\Delta t_{k i}$. For the detection, when the RMS is closed to 0 , the time-delays are used to compute the parameters of the location of the event such as azimuth, phase velocity, amplitude, etc. For better localization, we have the possibility to play on the variables such as window length, frequencies bands, etc. The Graphic PMCC (GPMCC) software provided by CTBTO, was used to visualize detections characteristics in the time-frequencies domain by plotting the azimuth, phase velocity (speed), amplitude, and duration of the infrasound waves.

The hourly satellite precipitation images have been exploited in their mapped format to observe the spatial distribution of the precipitation.

\section{Results and Discussions}

\subsection{Description Mesoscale Convective System (MCS) of April 9, 2018}

Infrared satellite images (Figure 1) show the spatial distribution of precipitations (blue to red colour) between 12:00 and 2:00 am in northeast Cote d'Ivoire 


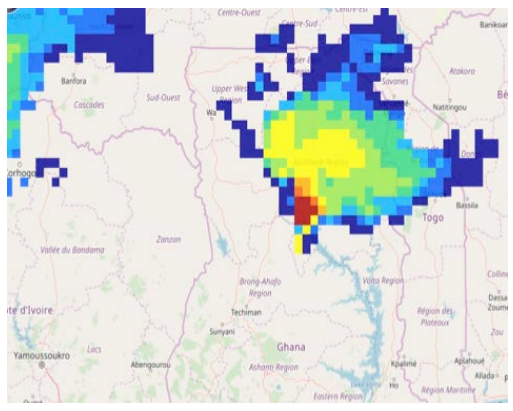

(a)

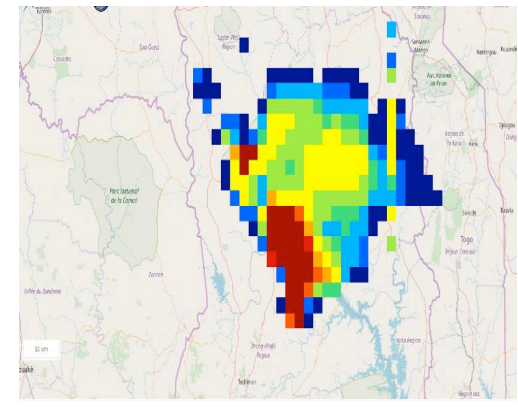

(b)

Figure 1. MCS infrared satellite precipitation image of April 92018 between 12 AM and 1 $\mathrm{AM}$ (a) and $1 \mathrm{AM}$ and $2 \mathrm{AM}$ (b). The high precipitation area (in red) reaches 96 $\mathrm{mm} /$ hour (https://sharaku.eorc.jaxa.jp/GSMaP/).

and northern Ghana. The MCS that generated these rainfalls came from the east of the portable infrasound array (I68CI) located in the Comoe National park and moves west over West Africa [11]. It was born on April 08, 2018, between 5:00 and 6:00 pm. Also, Figure 1(a) shows the spatial structure of this MCS between 12:00 and 1:00 am on April 9, 2018, with a rainfall of $96 \mathrm{~mm} /$ hour and a single zone of high precipitation located in the South. This rainfall zone has a diameter of about $110 \mathrm{~km}$ and covers the area between $2.31^{\circ} \mathrm{W}-0.69^{\circ} \mathrm{E}$ and $8.12^{\circ} \mathrm{N}-$ $10.14^{\circ} \mathrm{N}$. This region corresponds approximately to $12,000 \mathrm{~km}^{2}$ greater than that studied $\left(\sim 5000 \mathrm{~km}^{2}\right)$ by [11] for some MCSs in the Sahel.

The spatial distribution of the total rainfall was obtained between 1:00 and 2:00 am. Figure 1(b) clearly shows a division of the MCS structure into 2 distinct subsystems under the effect of internal and external constraints not well known but related to convection:

- A smaller subsystem in the north, associated with an area of intense rainfall of about $30 \mathrm{~mm} /$ hour and located at $9.5^{\circ} \mathrm{N}-2^{\circ} \mathrm{E}$;

- A large subsystem in the south, associated with a zone of high rainfall of about $96 \mathrm{~mm} /$ hour and located at $8.8^{\circ} \mathrm{N}-1.4^{\circ} \mathrm{E}$. These two daughter cells are respectively $200 \mathrm{~km}$ and $260 \mathrm{~km}$ away from I68CI station.

\subsection{Subdivision Signature of the MCS in Two Subsystems on Infrasound Data}

\subsubsection{On Histogram 1D}

The histogram in Figure 2 shows significant detections between $60^{\circ}$ and $100^{\circ}$ of azimuth over the time window 12:00 and 3:00 am. We notice two peaks of detections of 50 and 15 associated respectively with the $70^{\circ}$ and $90^{\circ}$ azimuths. These two azimuths correspond to those of the two MCS subsystems detected on April 9, 2018 (see Section 3.1). However, two other detections are observed between these two peaks at the $80^{\circ}$ azimuth. The presence of this minimum clearly shows the existence of two storm cells resulting from the division of the same MCS. Moreover, the detection peaks at $70^{\circ}$ and $90^{\circ}$ azimuth are associated with $2.3 \mathrm{~Hz}$ and $1 \mathrm{~Hz}$ frequencies respectively in two dominant directions which correspond to those of the two subsystems located $\sim 200 \mathrm{~km}$ and $\sim 260 \mathrm{~km}$ from I68CI station. 


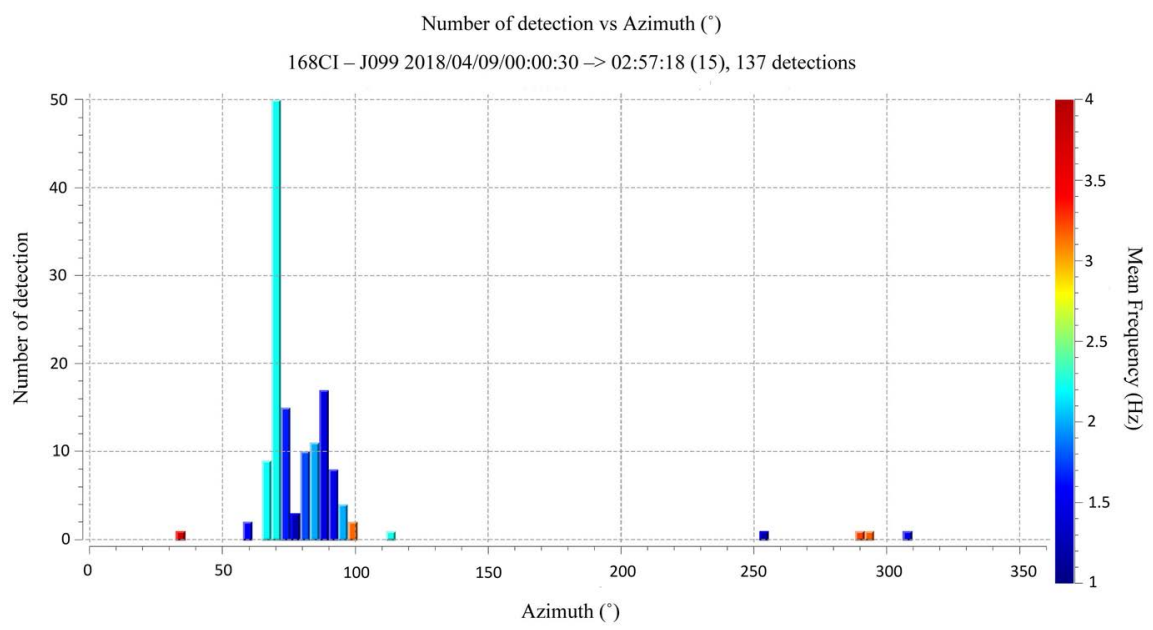

Figure 2. Histogram 1D plotted between $12 \mathrm{AM}$ and $3 \mathrm{AM}$ on April 09. The detections are more important between $60^{\circ}$ and $100^{\circ}$ azimuth. There are detection peaks of 50 and 15 from the azimuth $70^{\circ}$ and $90^{\circ}$ respectively.

These observations clearly show that the sources of emission of infrasound acoustic signals closest to a measuring station have higher emission frequencies than those more distant.

\subsubsection{On the Polar Plot}

Figure 3 shows on polar plot two separate family pixels (detections): the first on $72^{\circ}$ radial and the second on $90^{\circ}$ radial azimuth with velocity in the range [300 350] $\mathrm{m} / \mathrm{s}$ typical of the mean speed of infrasound signals propagation in the atmosphere. These families' pixels correspond to the separated subsystems. One can be seen that the second convective subsystem from $90^{\circ}$ azimuth consists of two parts: an isolated cell and a grouped cell with velocity values of $300 \mathrm{~m} / \mathrm{s}$ and $330 \mathrm{~m} / \mathrm{s}$ respectively.

In the arrival time of the infrasound waves detected by the I68CI station, the isolated cell is in advance of the grouped cells. This isolated cell seems to have emerged first and in its degeneration phase, the grouped cells in the active phase have formed.

\subsubsection{On Scatter Plot}

Figure 4 shows all observed detections in pixels and the trajectory of the MCS in the black line. The organization of these pixels from 12:00 to 4:00 am of April 9, 2018, defines two-time windows from which the analyses can be conducted. Indeed:

- Between 12:00 and 1:00 am, the convective system moves along the $70^{\circ}$ azimuth, (i.e. east of the station, see Figure 1(a));

- Between 1:00 and 4:00 am, there is a division of the MCS into two distinct sub-systems. The first subsystem (the northern subsystem) continues to move from east to west with an azimuth of $70^{\circ}$ while the second subsystem (the southern subsystem) moves a little further south of the station with curvilinear trajectories from the source of $70^{\circ}$ to $100^{\circ}$ of azimuth (Figure 4). 


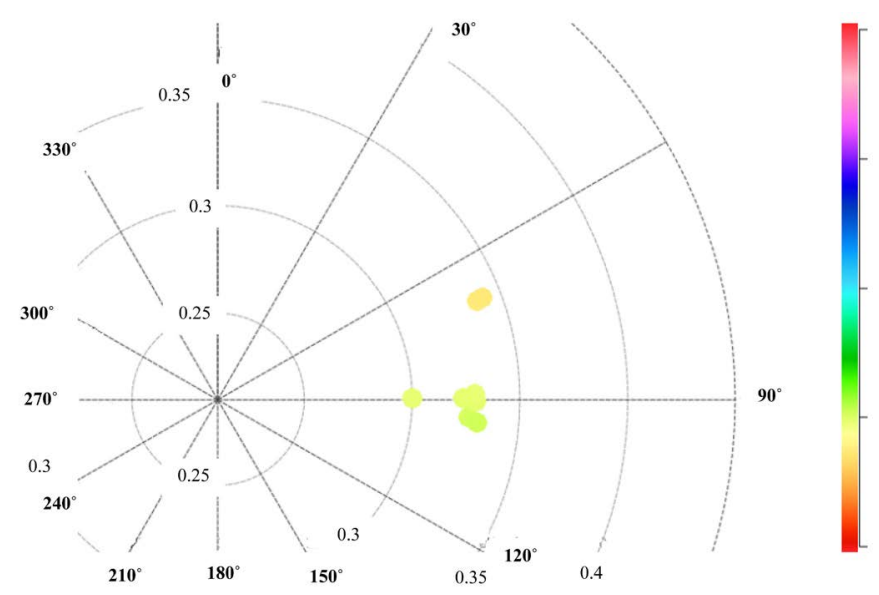

Figure 3. Polar plot between $1 \mathrm{AM}$ and $2 \mathrm{AM}$ on April 9. We have two separate family pixels: the first on $72^{\circ}$ radial and the second on $90^{\circ}$ radial azimuth with celerity between $0.3 \mathrm{~km} / \mathrm{s}$ and $0.35 \mathrm{~km} / \mathrm{s}$. These families' pixels represent the separated subsystems.

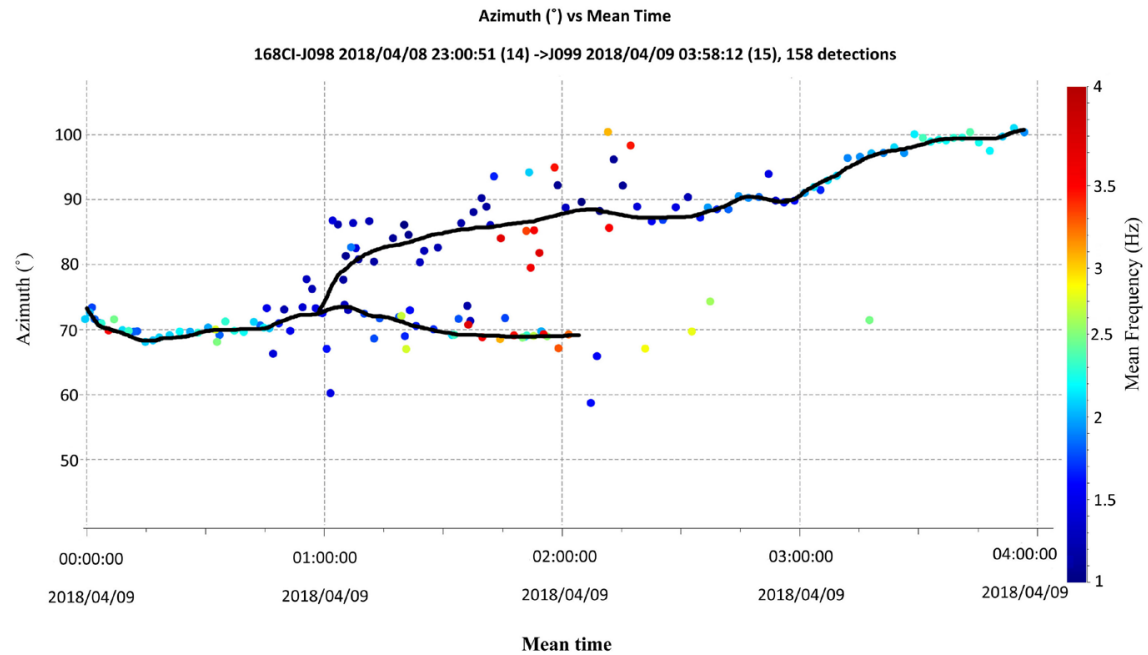

Figure 4. Scatter plot of MCS between 12 AM and 4 AM on April 9. The black line shows the roughly moving in relation to the pixels (detections) of the MCS and Subsystems of the MCS.

Also, the first subsystem stopped emitting signals detectable by I68CI around 2:00 am; just 1 hour after the MCS was split into two subsystems, while the second subsystem continued to emit infrasonic waves until 4:00 am. These results are in line with the work of [11], who showed that the separation of the MCS is mainly associated with the weakening of convection in one subsystem.

\subsection{Discussions}

Event detection by the PMCC method is performed according to the coherence of the measured signal. Indeed, for detections, delays are used to calculate the azimuth and phase velocity of the signal [16]. Using such an approach, different coherent wave systems can be differentiated by their time-frequency signature and their azimuth. Thus, the PMCC method allows the detection of two infra- 
sound waves with different azimuth and frequency that arrive at the infrasound station at the same time. This is the case of the infrasound signals emitted by the two subsystems of the MCS and detected by I68CI after the separation of the system. These two subsystems do not have the same frequency and the same azimuth.

By associating a keraunic level and lightning to the determination of the gravity waves (GW) detected by the I17CI station, the authors [8] studied the convective activity over West Africa produced by thunderstorms. The frequency band of the GWs used for their studies is between $10^{-4}$ and $10^{-3} \mathrm{~Hz}$. Besides, the present study uses infrasound waves directly emitted by the storm or MCS on the frequency band [0.1 - 4] Hz similar to that used by the IMS and found that infrasound waves are generated during strong air mass movements. These air mass displacements are produced by airplanes, thunderstorms or MCS, etc. These generated infrasound waves can be measured by micro-barometers in the same frequency band $[0.1-4] \mathrm{Hz}$ in which we worked.

\section{Conclusions and Perspectives}

The splitting characteristics of the MCS over West Africa have been investigated using infrasound data from a mobile array I68CI installed into the Comoé National Park, in the northeast of Cote d'Ivoire. The detection, based on the consistency of the signal, uses the time-delays to compute the signal azimuth and phase velocity and a Graphic PMCC software was used to analyze and visualize data. The results show that the MCS observed on April 9, 2018, in northern Ghana, was divided into two subsystems with $70^{\circ}$ and $90^{\circ}$ azimuths respectively and located $200 \mathrm{~km}$ and $260 \mathrm{~km}$ from the mobile array I68CI. These subsystems are observable on satellite images and their signatures appear clearly on the graphs. At about 1:00 am, the MCS was composed of one big system and was subsequently divided into two subsystems due to a weakening of convection. The northern subsystem $\left(70^{\circ}\right.$ azimuth) stopped emitting infrasound waves detectable by the I68CI at 2:00 am while the southern subsystem (90 azimuth) continued emitting infrasound waves until 4:00 am.

Infrasound data would improve our understanding of the mechanisms which interact with eastern wave over West Africa. Indeed, the MCSs displacement is superimposed on the eastern waves of the middle troposphere over West Africa during their life cycle and they generate a lot of gravitational waves (GW).

\section{Acknowledgements}

The authors thank the University Felix Houphouet Boigny (UFHB, Côte d'Ivoire), the Station Géophysique de LAMTO, and the LAboratoire des Sciences de la Matière, de l'Environnement et de l'Energie Solaire (LASMES), which allowed us to complete this work. They thank also the CTBTO for providing the infrasound portable array (I68CI), scientific expertise, and training. Finally, the authors are grateful to the CEA (Commission à l'Energie Atomique, France) for 
the capacity building courses they have attended and to the anonymous reviewers for their comments and suggestions to improve this work.

\section{Conflicts of Interest}

The authors declare no conflicts of interest regarding the publication of this paper.

\section{References}

[1] Hedlin, M.A.H., Berger, J. and Vernon, F.L. (2002) Surveying Infrasonic Noise on Oceanic Islands. Pure and Applied Geophysics, 159, 1127-1152. https://doi.org/10.1007/s00024-002-8675-1

[2] Christie, D.R. and Campus, P. (2010) The IMS Infrasound Network: Design and Establishment of Infrasound Stations. In: Infrasound Monitoring for Atmospheric Studies, Springer, Berlin, 29-75. https://doi.org/10.1007/978-1-4020-9508-5_2

[3] Marchetti, E., Ripepe, M., Campus, P., Le Pichon, A., Brachet, N., Blanc, E., Gaillard, P., Mialle, P. and Husson, P. (2019) Infrasound Monitoring of Volcanic Eruptions and Contribution of ARISE to the Volcanic Ash Advisory Centers. In: Le Pichon, A., Blanc, E. and Hauchecorne, A., Eds., Infrasound Monitoring for Atmospheric Studies, 2nd Edition, Springer, Dordrecht, 1141-1162.

https://doi.org/10.1007/978-3-319-75140-5_36

[4] Johnson, J.B. and Ripepe, M. (2011) Volcano Infrasound: A Review. Journal of Volcanology and Geothermal Research, 206, 61-69. https://doi.org/10.1016/j.jvolgeores.2011.06.006

[5] Marty, J., Ponceau, D. and Dalaudier, F. (2010) Using the International Monitoring System Infrasound Network to Study Gravity Waves. Geophysical Research Letters, 37, L19802. https://doi.org/10.1029/2010GL044181

[6] Edwards, W.N., Brown, P.G. and ReVelle, D.O. (2006) Estimates of Meteoroid Kinetic Energies from Observations of Infrasonic Airwaves. Journal of Atmospheric and Solar-Terrestrial Physics, 68, 1136-1160. https://doi.org/10.1016/j.jastp.2006.02.010

[7] Farges, T. and Blanc, E. (2010) Characteristics of Infrasound from Lightning and Sprites near Thunderstorm Areas. Journal of Geophysical Research, 115, A00E31. https://doi.org/10.1029/2009JA014700

[8] Blanc, E., Farges, T., Le Pichon, A. and Heinrich, P. (2014) Ten Year Observations of Gravity Waves from Thunderstorms in Western Africa. Journal of Geophysical Research: Atmospheres, 119, 6409-6418. https://doi.org/10.1002/2013JD020499

[9] Le Barbe, L. and Lebel, T. (1997) Rainfall Climatology of the HAPEX-Sahel Region during the Years 1950-1990. Journal of Hydrology, 188-189, 43-73. https://doi.org/10.1016/S0022-1694(96)03154-X

[10] D'Amato, N. and Lebel, T. (1998) On the Characteristics of the Rainfall Events in the Sahel with a View to the Analysis of Climatic Variability. International Journal of Climatology, 18, 955-974. https://doi.org/10.1002/(SICI)1097-0088(199807)18:9<955::AID-JOC236>3.0.CO;2-6

[11] Mathon, V. and Laurent, H. (2001) Life Cycle of the Sahelian Mesoscale Convective Cloud Systems. Quarterly Journal of the Royal Meteorological Society, 127, 377-406. https://doi.org/10.1002/qj.49712757208

[12] Kouassi, B., Diawara, A., Kouadio, Y.K., Schayes, G., Yoroba, F., Kouassi, A.A., Za- 
hiri, E.-P. and Assamoi, P. (2012) Numerical Study of a West African Squall Line Using a Regional Climate Model. Atmospheric and Climate Sciences, 2, 14-22. https://doi.org/10.4236/acs.2012.21003

[13] Setiawati, M.D. and Miura, F. (2016) Evaluation of GSMaP Daily Rainfall Satellite Data for Flood Monitoring: Case Study. Kyushu Japan Journal of Geoscience and Environment, 4, 101-107. https://doi.org/10.4236/gep.2016.412008

[14] Ushio, T., Sasashige, K., Kubota, T., Shige, S., Okamoto, K. and Aonashi, K. (2009) A Kal-Man Filter Approach to the Global Satellite Mapping of Precipitation (GSMaP) from Combined Passive Microwave and Infrared Radiometric Data. Journal of Meteorological Society of Japan, 87A, 137-151.

https://doi.org/10.2151/jmsj.87A.137

[15] Aonashi, K., Awaka, J., Hirose, M., Kozu, T., Kubota, T., Liu, G., Shige, S., Siga, S., Seto, S., Takahashi, N. and Takayabu, Y.N. (2009) GSMaP Passive Microwave Precipitation Retrieval Algorithm: Algorithm Description and Validation. Journal of Applied Meteorology, 87A, 119-136. https://doi.org/10.2151/jmsj.87A.119

[16] Cansi, Y. (1995) An Automatic Seismic Event Processing for Detection and Location: The PMCC Method. Geophysical Research Letters, 22, 1021-1024.

https://doi.org/10.1029/95GL00468 